\title{
KMT2D maintains neoplastic cell proliferation and global histone H3 lysine 4 monomethylation
}

\author{
Changcun Guo ${ }^{1,2}$, Lee H. Chen ${ }^{1,2}$, Yafen Huang ${ }^{1,2}$, Chun-Chi Chang ${ }^{1,2}$, Ping Wang ${ }^{1,2}$, \\ Christopher J. Pirozzi ${ }^{1,2}$, Xiaoxia Qin ${ }^{4}$, Xuhui Bao ${ }^{1,2}$, Paula K. Greer ${ }^{1,2}$, Roger E. \\ McLendon $^{1,2}$, Hai Yan ${ }^{1,2}$, Stephen T. Keir ${ }^{1,3}$, Darell D. Bigner ${ }^{1,2}$, Yiping He ${ }^{1,2}$ \\ ${ }^{1}$ The Preston Robert Tisch Brain Tumor Center at Duke and Pediatric Brain Tumor Foundation Institute, Duke University, \\ Durham, NC \\ 2 Department of Pathology, Duke University, Durham, NC \\ ${ }^{3}$ Department of Surgery, Duke University, Durham, NC \\ ${ }^{4}$ Institute for Genome Sciences and Policy, Duke University, Durham, NC \\ Correspondence to: Yiping He, email: Yiping.he@duke.edu
}

Keywords: MLL2, isogenic cell line, gene knockout, enhancer

Received: October 30, $2013 \quad$ Accepted: November 1, $2013 \quad$ Published: November 3, 2013

This is an open-access article distributed under the terms of the Creative Commons Attribution License, which permits unrestricted use, distribution, and reproduction in any medium, provided the original author and source are credited.

\section{ABSTRACT:}

KMT2D (lysine (K)-specific methyltransferase 2D), formerly named MLL2 (myeloid/lymphoid or mixed-lineage leukemia 2, also known as ALR/MLL4), is a histone methyltransferase that plays an important role in regulating gene transcription. In particular, it targets histone H3 lysine 4 (H3K4), whose methylations serve as a gene activation mark. Recently, KMT2D has emerged as one of the most frequently mutated genes in a variety of cancers and in other human diseases, including lymphoma, medulloblastoma, gastric cancer, and Kabuki syndrome. Mutations in KMT2D identified thus far point to its loss-of-function in pathogenesis and suggest its role as a tumor suppressor in various tissues. To determine the effect of a KMT2D deficiency on neoplastic cells, we used homologous recombination- and nuclease-mediated gene editing approaches to generate a panel of isogenic colorectal and medulloblastoma cancer cell lines that differ with respect to their endogenous KMT2D status. We found that a KMT2D deficiency resulted in attenuated cancer cell proliferation and defective cell migration. Analysis of histone H3 modifications revealed that KMT2D was essential for maintaining the level of global H3K4 monomethylation and that its enzymatic SET domain was directly responsible for this function. Furthermore, we found that a majority of KMT2D binding sites are located in regions of potential enhancer elements. Together, these findings revealed the role of KMT2D in regulating enhancer elements in human cells and shed light on the tumorigenic role of its deficiency. Our study supports that KMT2D has distinct roles in neoplastic cells, as opposed to normal cells, and that inhibiting KMT2D may be a viable strategy for cancer therapeutics.

\section{INTRODUCTION}

One striking theme emerging from recent findings from high throughput sequencing-based cancer genetic studies is that chromatin remodeling and histone modulators are frequently altered and that the resulting aberrations promote cancers. The best examples include inactivating mutations in genes encoding histone lysine methyltransferases KMT2C (also known as MLL3), KMT2D (also known as MLL2/ALR/MLL4), and their associated histone demethylase KDM6A (also known as UTX) [1-17]. The original medulloblastoma exome sequencing led to the discovery of frequent mutations in the histone lysine methyltransferase gene KMT2D/ $M L L 2$ and its homolog KMT2C/MLL3, which were not previously linked to cancer [13]. Subsequent 
comprehensive studies involving larger numbers of wellclassified medulloblastoma samples have significantly extended these genetic findings and further confirmed that dysregulation of the KMT2D/KMT2C pathway, including mutations in a KMT2D- and KMT2C-associated demethylase KDM6A, plays an important role in driving various types of human medulloblastomas [14-17]. The identified KMT2D alterations span across the whole gene and were most frequently heterozygous frameshift or nonsense mutations that ablated the carboxyl-terminal methyltransferase enzymatic domain (SET domain). These findings defined this pathway as a bona fide medulloblastoma oncogenic pathway.

In addition to its role in medulloblastoma, subsequent studies have found that $K M T 2 D$ is frequently mutated in other cancers, including $89 \%$ of follicular lymphoma and $20 \%-30 \%$ of diffusive large B-cell lymphoma [8, 9]. KMT2C is also mutated in colorectal cancer $[1,10]$. Additional cancers that have recently been found to be driven by an aberrant KMT2D/KMT2C pathway, with frequencies ranging from $5 \%$ to $40 \%$, include renal [2], prostate [18], bladder [5], gastric [11], hepatic [3] and lung cancer [6, 19]. Furthermore, germline $K M T 2 D$ inactivation has recently been found to be the major cause of Kabuki syndrome [20], a rare, congenital pediatric disorder characterized by intellectual disabilities; de novo mutations in KMT2D and other chromatin-modifying genes have been associated with congenital heart disease [21]. Collectively, these findings place the KMT2D/KMT2C pathway among the most frequently mutated pathogenic pathways that drive human diseases. The alterations of KMT2D/KMT2C suggest new opportunities for therapeutics and highlight an urgent need to understand their functional mechanism and therapeutic implications.

Modulation of chromatin accessibility through histone methylations is essential in regulating eukaryotic gene transcription. For example, histone $\mathrm{H} 3$ lysine 4 (H3K4) methylation by the histone methyltransferase family of genes is associated with active gene transcription and plays an important role in development [22]. Among the four $\mathrm{H} 3 \mathrm{~K} 4$ methyltransferase genes with similar structural domains, KMT2A (formerly named $M L L)$ is frequently involved in genetic alterations in acute myeloid and acute lymphoblastic leukemia [23]. Its homologue, KMT2B (formerly named MLL4), has been found to be overexpressed in breast and colorectal cancer cell lines, although the pathological consequence of its overexpression is unclear [24]. The remaining pair of genes, KMT2C and KMT2D, shares a high degree of similarity in their structural domains and biochemical functions. For example, each of them associates with nuclear receptor coactivator 6 (NCOA6, also known as activating signaling cointegrator-2, ASC-2) to form a complex that contains other essential subunits, including a histone demethylase, KDM6A [28-30]. The KMT2C or
KMT2D complex has been found to play essential roles as a coactivator for transcriptional activation by nuclear hormone receptors, including retinoic acid receptors, in Hox gene transcription, and in regulating adipogenesis [31-35].

Apart from the genetic evidence, the role of KMT2C in tumorigenesis and in cancer progression was first suggested by a KMT2C knockout mouse model that developed ureter epithelial tumors [36]. Furthermore, knockdown of $K M T 2 C$ promoted the proliferation of hepatocellular carcinoma cancer cell lines in vitro [3]. In contrast, knockdown of $K M T 2 D$ resulted in reduced cancer cell proliferation and altered adhesion in HeLa cells [29]. This, together with the near absence of homozygous KMT2D inactivating mutations in medulloblastoma [16], led us to speculate that the role of the KMT2D deficiency in cancer is more complicated than simply driving tumor cell proliferation. To clarify the role of KMT2D in cancer cells, we employed somatic gene knockout approaches to generate a panel of isogenic KMT2D-deficient human cancer cell lines and determined the impact of a KMT2D deficiency on neoplastic cells. We further characterized KMT2D binding loci to reveal a link between KMT2D, global H3K4 monomethylation, and enhancer elements.

\section{RESULTS}

\section{KMT2D deficiency affects proliferation of neoplastic cells}

Somatic mutations of KMT2D were initially identified in medulloblastoma [13], thus we sought to first examine its role in human medulloblastoma cancer cell lines. The gigantic size of the KMT2D polypeptide (5537 amino acids with a molecular weight of $\sim 600$ $\mathrm{kDa}$ ) makes its gain-of-function study by overexpression difficult and inefficient. Since there are no known medulloblastoma cell lines with loss-of-function KMT2D mutations (e.g., frameshift mutations), we decided to use a somatic gene knockout strategy. We selected two human medulloblastoma cancer cell lines, D425MED and D283MED, and transiently transfected a pair of $K M T 2 D$-specific zinc-finger nucleases (ZFNs) to induce double strand break surrounding the codon for amino acid 3685 (Histidine, H3685) of KMT2D. The generation of a double-strand break led to error-prone non-homologous end joining (NHEJ), resulting in frequent mutations of $K M T 2 D$. Using this pair of ZFNs to mutate KMT2D in medulloblastoma cell lines, we introduced nucleotide alterations in one allele of $K M T 2 D$ through a single round of transient nuclease expression. We selected mutants with heterozygous frameshift mutations (e.g., a small deletion of four bases, as shown in Fig. S1A, that made the allele "null") as they best resembled somatic alterations 
identified in human cancers. Since the enzymatic SET domain is located at the carboxyl-terminus that was expected to be ablated by the frameshift mutations, it was unlikely the mutant allele would generate truncated polypeptides possessing gain-of-function enzymatic activity. These isogenic heterozygous KMT2D mutantharboring cell lines were defined as KMT2D-deficient $\left(K M T 2 D^{+/}\right)$derivatives thereafter.

To determine the biological consequence of KMT2D deficiency, we measured the proliferation of KMT2Ddeficient cells. As shown in Fig. 1A, in comparison to the parental cells, $K M T 2 D^{+/}$isogenic cell lines derived from both D425MED and D283MED had slightly, but reproducibly decreased proliferation kinetics under standard culture conditions in vitro. Consistent with a slower proliferation rate, colony formation assays revealed a compromised ability for single $K M T 2 D^{+/}$cells to form colonies, as reflected by both the numbers and sizes of colonies formed in 6-well plate assays over the course of 12 days (Fig. 1B).

To decide if the aforementioned effect was specific only to medulloblastoma cell lines, we expanded our experiments to additional cellular contexts. For this purpose, we generated KMT2D-deficient isogenic cell lines derived from colorectal carcinoma lines, including HCT116 and DLD-1. To exclude potential artifacts resulted from particular gene-editing methods, we used different approaches to generate these isogenic cell lines. As we described previously, KMT2D ${ }^{-/}$HCT116 cell lines were obtained by recombinant adeno-associated virus (rAAV)-mediated homologous recombination [35]. The
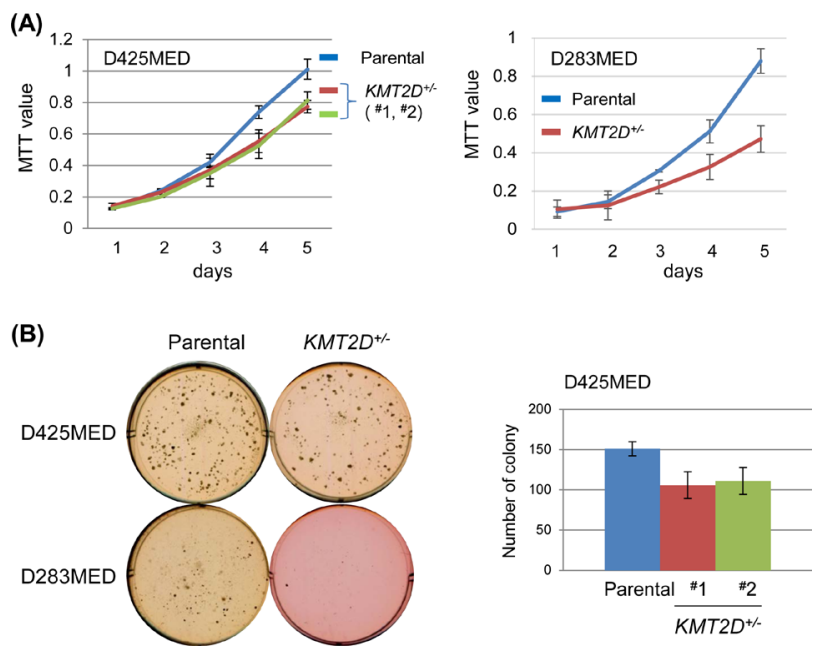

Figure 1: KMT2D deficiency affects proliferation of medulloblastoma cell lines. (A) Proliferation of D425MED and D283MED cell lines was measured by MTT assay (for D425MED, each mutant vs. parental: $p=0.01$; for D283MED, $p<0.01$ ). (B) Cell propagation was measured by colony formation in soft agar. For D425MED cell lines, the number of colonies was counted after a 14-day incubation; representative results (from triplicate wells) from one of three experiments was shown (for each mutant vs. parental: $p<0.05$ ). isogenic $K M T 2 D^{-/}$DLD-1 cell line was obtained by using ZFN- and rAAV- mediated approach sequentially for the first and second allele gene knockout (Fig. S1B). We measured the proliferation of these $K M T 2 D^{-/}$isogenic cell lines in comparison to their respective parental cell lines. Again, KMT2D knockout resulted in attenuated cell proliferation in both HCT116 and in DLD-1 and compromised the ability of the cells to form colonies (Fig. 2A-B). To ascertain that the compromised cell proliferation was not specific only for the in vitro culture condition, we performed in vivo tumorigenicity assays of paired parental versus $K M T 2 D^{-/}$isogenic HCT116 cell lines using subcutaneous athymic mouse models. As seen in Fig. 2C, mice receiving KMT2D-deficient cell lines had overall longer survival as these cells also had diminished capacity to propagate in vivo when compared to the parental cell line. These results, together with those described above and previous findings from the HeLa cell line [29], suggest that KMT2D inactivation compromises cell proliferation capacity in a wide range of human neoplastic cellular contexts.

\section{KMT2D deficiency attenuates cell migration}

Aberrant cell migration is frequently associated with cancers. In general, enhanced migration capacity is believed to be associated with tumor metastasis. On the contrary, compromised cell migration may also make cells more susceptible to transformation. The latter is best illustrated by medulloblastoma tumorigenesis in which granule neuronal precursors fail to migrate to their destination over time and therefore acquire additional time for mitosis and are more likely to be transformed [37-39]. Our previous experiments identified a group of KMT2D-regulated genes that are functionally linked to cell migration and extracellular matrices [35]. In addition, in HeLa cells, shRNA-mediated knockdown of KMT2D altered cell cytoskeleton structure and adhesion [29]. To determine if cell migration is generally regulated by KMT2D, we performed transwell assays for pairs of isogenic cell lines. As shown in Fig. 3, when allowed 16 hours for migration, parental D283MED, HCT116 and DLD-1 cells were able to migrate through transwell chamber inserts. In contrast, the migration of KMT2Ddeficient cells to the destination was attenuated. These results demonstrate that KMT2D inactivation attenuates neoplastic cell migration. Supporting this compromised cell migration are results from previous gene expression profiling in $K M T 2 D^{-/}$HCT116 that revealed reduced expression of genes involved in cytoskeleton organization and calcium signaling, including the cluster of S100A family genes [35]. 


\section{KMT2D regulates $\mathrm{H} 3 \mathrm{~K} 4$ monomethylation and is associated with enhancer elements}

Because KMT2D functions as a histone methyltransferase, we examined the global histone modification profiles in KMT2D-null cells. In particular, given their link to the KMT2D complex, we examined the H3K4me1, H3K4me2, H3K4me3 and H3K27ac in the KMT2D ${ }^{-/}$HCT116 cell lines compared to the parental lines. Notably, the level of H3K4me1 displayed the greatest reduction in the $K M T 2 D^{-/}$cell lines, while levels of other modifications only displayed minor changes (Fig. 4A). As $\mathrm{H} 3 \mathrm{~K} 4 \mathrm{mel}$ is primarily associated with global enhancer elements [40], these results prompted us to further examine the potential link between KMT2D and enhancers. We have previously mapped the global binding profile of KMT2D and revealed a large number of KMT2D bindings sites that were located outside of proximal promoter regions [35]. To further probe the link of KMT2D to enhancers, we used a stringent criteria to select 1605 KMT2D binding sites in the HCT116 cell line - identified in our previous study - and compared these loci to the HCT116 cell line histone modification profiles identified by the ENCODE project (http:// genome.ucsc.edu/ENCODE/) [35, 41] (Table S1). We found that $\sim 87 \%(1403 / 1605, \mathrm{p}<0.0001)$ of KMT2D binding sites overlapped with regions positive for H3K4me1, an enhancer mark, and $75 \%$ (1207/1605, $\mathrm{p}<0.0001$ ) of binding sites overlapped with regions positive for $\mathrm{H} 3 \mathrm{~K} 4 \mathrm{me} 1$ and $\mathrm{H} 3 \mathrm{~K} 27 \mathrm{ac}$, an active enhancer mark (Table S1). In fact, a comparison of the chromatin immunoprecipitation-sequencing (ChIP-seq) peaks of 19 transcriptional factors from ENCODE found that KMT2D had the highest fraction of binding sites that overlapped with H3K4me1 positive regions in HCT116 cell line (Table S2). These results support the link between KMT2D and H3K4 monomethylation and suggest that KMT2D frequently resides in enhancer elements. To further confirm these results, we examined the level of H3K4me1 on a set of KMT2D-bound putative enhancer loci in $K M T 2 D^{--}$HCT116 cells. Notably, ChIP-qPCR revealed a reduced level of $\mathrm{H} 3 \mathrm{~K} 4 \mathrm{me} 1$ in these loci in the $K M T 2 D^{--}$cell lines when compared to the parental cell line (Fig. 4B). These results suggest that KMT2D resides in and regulates a set of enhancers. In agreement with this finding, another group recently used one of the $K M T 2 D^{-1-}$ HCT116 cell lines that we generated and demonstrated a similar link of KMT2D to H3K4 monomethylation and global enhancer elements [42].

KMT2C and KMT2D have similar structural domains, and prior studies suggest similar biochemical functions $[34,36]$. We sought to determine if the above global reduction of $\mathrm{H} 3 \mathrm{~K} 4 \mathrm{me} 1$ in the $K M T 2 D^{-/}$cell line was due to the loss of both KMT2D and KMT2C in the $K M T 2 D^{-/} \mathrm{HCT} 116$ cell line, which harbors an endogenous homozygous $K M T 2 C$ frameshift inactivating mutation $[10,35]$. Human colorectal cancer cell line DLD-1 has the wild-type $K M T 2 C$ gene [10]. We therefore examined the H3K4me1 level in the KMT2D-null isogenic DLD-1 cell line. Interestingly, KMT2D knockout in DLD-1 also resulted in a reduction in the level of H3K4me1 (Fig. 4C).
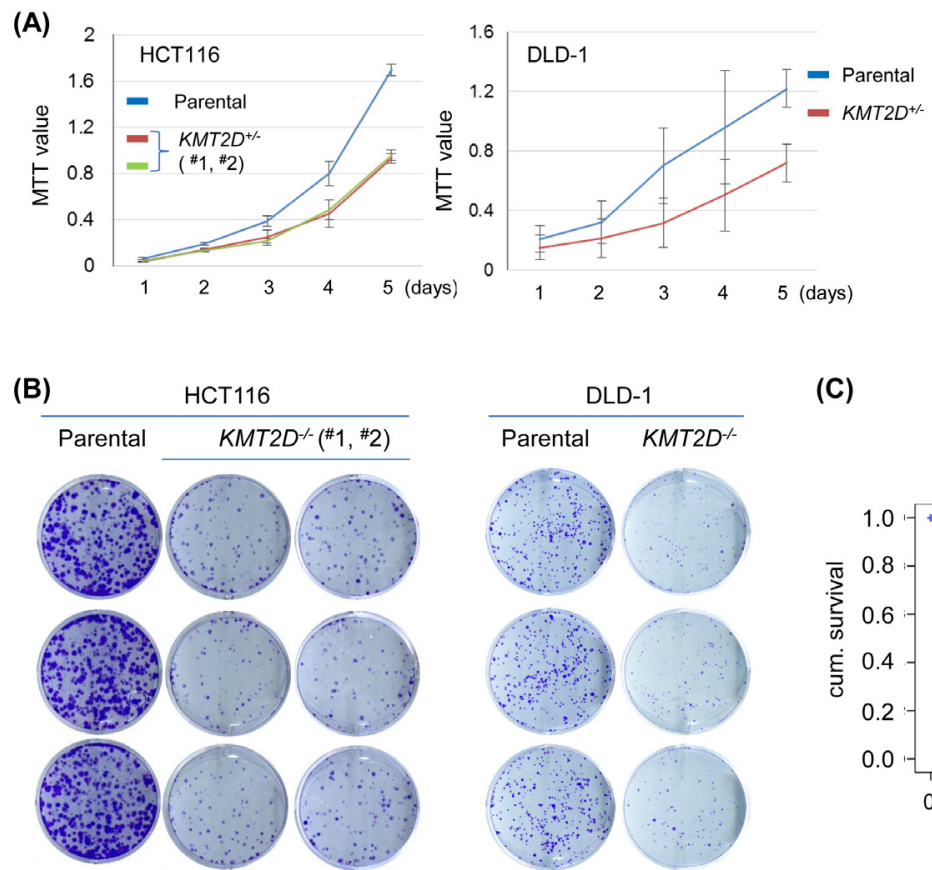

(C)

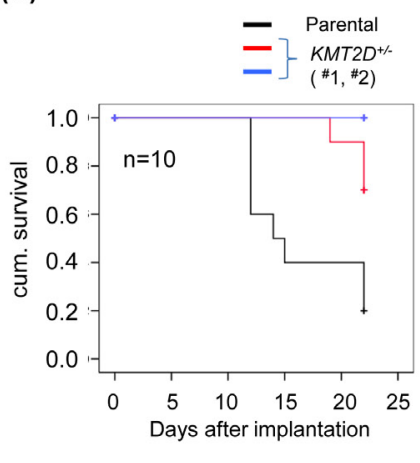

Figure 2: KMT2D deficiency affects proliferation of colorectal cell lines. (A) Proliferation of HCT116 and DLD-1 cell lines was measured by MTT assay (for HCT116, each mutant vs. parental: $p<0.001$; for DLD-1, $p<0.01$ ). (B) Cell propagation was measured by the colony formation assay. (C) Kaplan-Meier survival curve analysis of mice receiving parental or KMT2D ${ }^{-/}$HCT116 cell lines subcutaneously; 10 mice were included for each cell line (mutant \#1 vs. parental: $p=0.01$; mutant \#2 vs. parental: $p<0.001$ ). 
This result suggests that the KMT2D gene has a unique role in maintaining global $\mathrm{H} 3 \mathrm{~K} 4 \mathrm{me} 1 \mathrm{level}$, and that KMT2C and KMT2D may have non-redundant roles in certain cellular contexts.

\section{The enzymatic SET domain of KMT2D is required for effective $\mathrm{H} 3 \mathrm{~K} 4$ monomethylation in vivo}

The $K M T 2 D^{-/}$HCT116 cell lines had homozygous insertions in both $K M T 2 D$ alleles that resulted in altered splicing transcripts with no detectable KMT2D polypeptides [35]. Despite this KMT2D-null genotype, the recent study using our $K M T 2 D^{-/}$cell line named this line as a KMT2D $\triangle$ SET mutant, implying a simple loss of the SET domain [42]. To determine the direct role of the enzymatic SET domain of KMT2D in vivo, we generated a cell line carrying homozygous SET domain-truncated

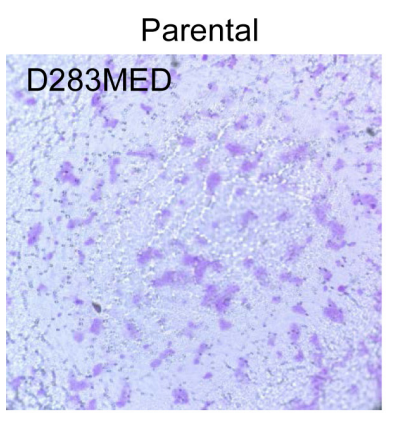

KMT2D-deficient
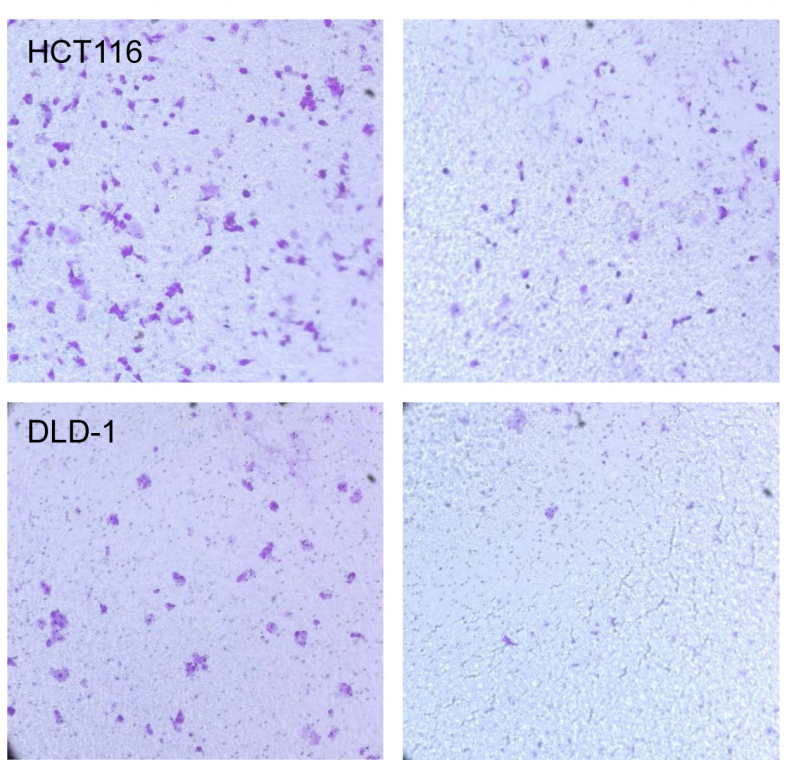

Figure 3: KMT2D deficiency attenuates cell migration. Transwell assays were performed for D283MED, HCT116 and DLD-1 cell lines. Equal numbers of both parental and KMT2D-deficient cells were plated out in the transwell upper chamber; cells were allowed to migrate for 16 hours before those on the destination side were fixed and stained with crystal violet. Representative results from one of three independent experiments were shown. The parental D425MED cell line failed to migrate in the transwell, possibly due to its suspending nature, and was not included in this assay.
KMT2D alleles. Specifically, we modified our endogenous gene fusion strategy such that a six-glycine linker coding sequence, a triple-Flag coding sequence and a stop codon (gFlag: glycine-linker plus Flag) were inserted into the genome preceding the SET domain coding sequence in the KMT2D gene (Fig. 5A). We found that this modification overcame the previous alternative splicing issue and the expected fusion transcript and KMT2D $\Delta$ SET-gFlag polypeptide (simplified as KMT2D $\triangle$ SET hereafter) could be detected in this cell line (KMT2D $\triangle S E T^{\text {FFlag/ }}$ gFlag) (Fig. S1C). While the chromatin binding of the KMT2D $\Delta$ SET mutant was detectable by ChIP, we found that the removal of the SET domain of KMT2D also led to a reduced level of H3K4me1 (Fig. S1C, Fig. 5B). Further supporting the important role of the SET domain in vivo, retarded cell proliferation was also observed in the KMT2D $\Delta$ SET expressing cell line (Fig. 5C). Together, these results support the notion that the enzymatic activity of KMT2D is directly involved in regulating H3K4me1 and maintaining neoplastic cell proliferation.

\section{DISCUSSION}

Chromatin remodeling and histone modulators are frequently altered and the resulting aberrations are associated with numerous types of cancers. The apparent loss-of-function alterations, including frameshift and nonsense mutations, suggest a tumor suppressor role for KMT2C and KMT2D. Intriguingly, knockdowns of KMT2C and KMT2D, each in a single cell type, yielded contradictive results in term of their impact on cancer cell proliferation $[3,29]$. Further adding to this complexity, the near absence of homozygous KMT2D mutations in medulloblastoma led to the speculation of an oncogenic dependency on KMT2D activity [16]. In an attempt to clarify the role of KMT2D in neoplastic cell proliferation, we characterized a panel of isogenic human cell lines, and provided evidence to support the notion that indeed, an inactivation of KMT2D may be detrimental to the ability of certain types of neoplastic cells to propagate. These findings suggest KMT2D has distinct and complicated impacts on normal versus cancer cells. While its loss in normal cells most likely leads to, or predisposes cells to, transformation, its activity may be beneficial to the proliferation of already-transformed cells. With the ever expanding list of new cancer genes, it becomes apparent that unlike most classic cytosolic oncogenic signaling cascades, those "nucleus-originated" aberrant events, such as chromatin remodeling and histone modifications, present a different type of challenge and complication. The biological findings presented here highlight such a complexity. Similarly, the link between KMT2D to neoplastic cell migration and adhesion revealed here and in the previous study raise more questions [29]. Although we identified differential expression of numerous genes relevant to regulating cell migration, it is unclear whether 
simply restoring the expression of these genes can reverse the migration phenotype. The challenge is best exemplified by the S100A family of genes, as it will be difficult to overexpress a cluster of genes simultaneously. Separately, the aberrant cytoskeleton structure in the KMT2D knockdown cells raises a different set of questions [29]. It is likely this can be caused by altered expression of certain genes; but we cannot rule out the possibility of transcription-independent events such as differential posttranslational protein modification. Finally, it is unclear if the KMT2D-dependent adhesion/migration is also true in normal cells, and if so, then what is its relevance to tumorigenesis.

Perhaps the most interesting finding is the revelation that KMT2D resides in and regulates enhancer elements in human cells. Our previous study identified genes regulated by KMT2D through the proximal promoter-based mechanism. The linkage of KMT2D to enhancer elements here provides a critical step toward understanding its regulatory mechanisms and its association to various types of cancers, as enhancer elements play essential yet diverse roles in cell type-dependent gene transcription [43]. This finding is in agreement with the enhancer-associated role of the Drosophila homolog gene, $\operatorname{Tr} r$ [44]. Furthermore,
(A)

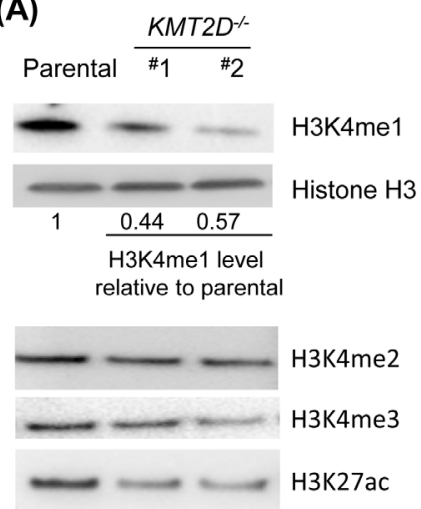

(B)

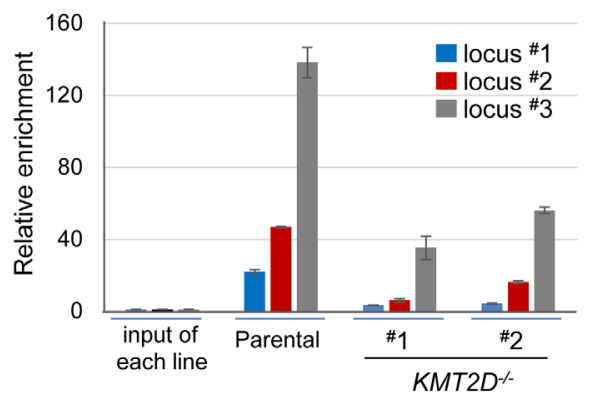

(C)

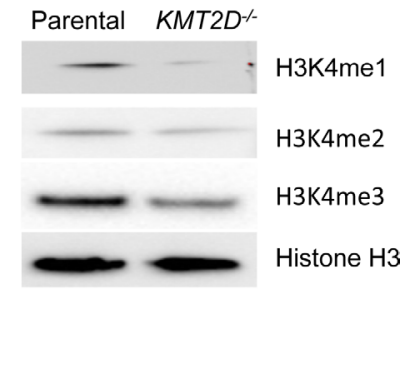

Figure 4: KMT2D regulates H3K4 monomethylation and is associated with enhancer elements. (A) Immunoblot analysis of histone modifications in the parental versus $K M T 2 D^{-/} \mathrm{HCT} 116$ cell lines. Representative results from one of at least three independent experiments were shown. The relative level of H3K4me1 was indicated; the level in the $K M T 2 D^{-/}$cell lines was typically between $40-60 \%$ of the level in the parental cells; other modifications had slight or no reduction. (B) Anti-H3K4me1 ChIP was performed and the H3K4me1 levels were examined in a subset of KMT2D-bound enhancer elements (marked by high H3K4me1 and low H3K4me3 (ENCODE), and located $>1$ kilobases (kbs) upstream of the transcriptional start sites (TSS) of the closest genes). Genes associated with locus \#1-3 (and the distance between their TSS and the putative enhancer elements) were CARD10 (5.4 kbs), WBSCR27 (8.1 kbs) and TRIM25 (2.1 kbs). (C) Anti-H3K4me1, H3K4me2 and H3K4me3 immunoblots in the isogenic pair of DLD-1 cell lines. Representative results from one of three independent experiments were shown.

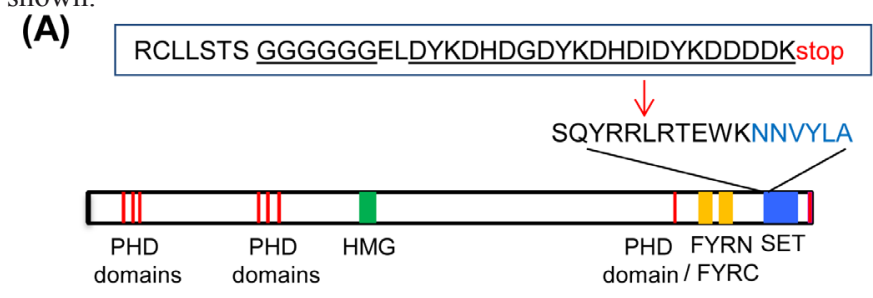

(B)

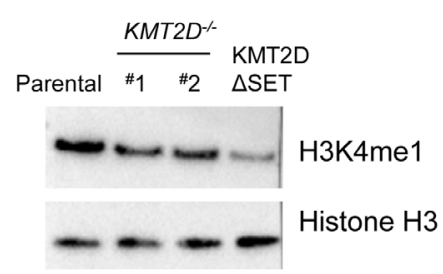

(C)

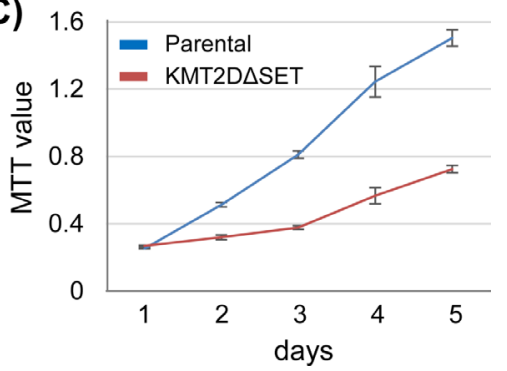

Figure 5: The enzymatic SET domain of KMT2D is required for effective H3K4 monomethylation in vivo. (A) The design of the SET domain truncated mutant, KMT2D $\triangle$ SET. The structural domains/motifs of KMT2D denoted the carboxyl-terminal enzymatic SET domain. An insertion, including a six-glycine linker and the triple Flag tags, was shown. (B) Anti-H3K4me1 Immunoblot in the isogenic set of HCT116 cell lines. Note the reduced H3K4me1 level in the KMT2D $\Delta$ SET expressing cell line. (C) Proliferation of KMT2D $\triangle$ SET expressing HCT116 cell line and the parental HCT116 cell line was measured by MTT assays. Representative results (from triplicate wells) from one of three experiments was shown $(p<0.001)$. 
our finding in cells harboring a SET domain truncated KMT2D mutant supports that KMT2D functions as a methyltransferase that adds monomethylation to $\mathrm{H} 3 \mathrm{~K} 4$, thereby playing a role in defining enhancer elements. It is notable that the finding in DLD-1, which, unlike HCT116, has functional KMT2C alleles, suggests that KMT2C cannot fully substitute for KMT2D in this cellular context. Further studies involving more cell types and in vitro enzymatic activity assays will clarify any distinct roles between KMT2C and KMT2D.

Enhancer elements have increasingly been recognized as critically involved in pathogenesis, as best exemplified by several recent studies $[45,46]$. The implication of KMT2D-enhancer link to our continuing research is apparent in the following ways: first, it will guide the search of KMT2D-regulated genes through not only promoter and proximal regulatory elements but also enhancer and distal element identification; second, it suggests the role of enhancer-mediated transcriptional regulation in tumorigenesis and prompts us to examine the possible roles of other histone modifiers in regulating enhancers in both normal development and in pathogenesis; and finally, it suggests a necessity to revisit focal copy number variations in cancer cells, especially copy loss, as it is possible that the aberrant KMT2D pathway promotes tumorigenesis not just through KMT2D mutations, but also through the loss of its target elements.

Exploiting epigenetic aberrations for cancer treatment has been recognized as feasible, with various therapeutic agents being used in clinics or in different stages of development [47]. While the underlying mechanism remains to be illuminated, the effect of a KMT2D deficiency in neoplastic cells' proliferation supports that, in some cases, targeting KMT2D may be a viable treatment strategy, a notion recently postulated based on genetic evidence [16]. For example, it is conceivable that targeting KMT2D may serve as part of a combinatory treatment regimen, provided that a cancerspecific delivery is possible.

\section{METHODS}

\section{Cell lines and somatic gene targeting}

HCT116 cell lines were described previously [35]. The DLD-1 cell line (ATCC, CCL-221) was cultured in RPMI-1640 medium supplemented with 10\% FBS. Medulloblastoma cell lines D425MED and D283MED were cultured in zinc option medium (Life Technologies, cat\# 10373017; supplemented with 10\% FBS). The rAAVmediated gene knockout was described previously [35]. For ZFN-mediated gene knockout, KMT2D-specific ZFN expression plasmids (Sigma, cat\# CKOZFND14397) were used to transfect cells in 6-well plates. Two days after transfection, cells were serially diluted, plated out in 96-well plates and cultured for 10-14 days before screening for KMT2D-mutant clones using Cel-I assays. Positive clones were sequenced and those with frameshift mutations were defined as null mutations and used for further studies. For homozygous KMT2D knockout in DLD-1, the $1^{\text {st }}$ allele was knockout by ZFN and the $2^{\text {nd }}$ allele was knockout by the previously described rAAVmediated strategy [35]. Homozygous knockout was confirmed by anti-KMT2D immunoblot using the antibody previously described [35].

\section{Nuclear extraction, immunoblot, chromatin immunoprecipitation (ChIP) and quantitative PCR}

Procedures for these experiments were previously described [35]. Antibodies used for ChIP and for immunoblot included: anti-H3K4me1 (Millipore, cat\#07-436), anti-H3K4me2 (Abcam, Cat\#: ab7766), anti-H3K4me3 (Millipore, cat\#: 07-473), and antiH3K27ac (Millipore cat\# 05-1334). Relative H3K4me1 levels were quantified using ChemiDoc MP Imaging System (Bio-Rad). Anti-Flag antibody for anti-Flag ChIP was previously described [35]. The same protocol was used for anti-H3K4me1 ChIP, except that the cells were cross-linked with $1 \%$ formaldehyde and sonicated with a Branson sonifier only. PCR primers used for ChIP-qPCR included: locus \#1 (CARD10): forward primer 5'- CAGGCTGGGAAAAGACAGAG-3' and reverse primer 5'-CTCCCTCCAACCACCTTGT-3'; locus \#2 (WBSCR27): forward primer 5'-GCTGACACACCCAGCTGATA-3' and reverse primer 5'- ACCCTCCAGTGGGTTAAAGC-3'; locus \#3 (TRIM25): forward primer 5'-GTGCAATAGGCATGCAACAG-3' and reverse primer 5-GGACCTGACTTCTCCCCATA-3'. Primers for other ChIP-qPCR were previously described [35].

\section{Comparison of KMT2D binding sites to regions identified by ENCODE}

KMT2D binding sites (Table S1) were from previous data analyzed by model-based analysis of ChIPSeq (MACS) [35, 48]. ENCODE data for H3K4me1, $\mathrm{H} 3 \mathrm{~K} 27 \mathrm{ac}$ and other transcriptional factors in the HCT116 cell line were downloaded from http://genome.ucsc.edu/ ENCODE [41]. Comparative analysis of the ENCODE data and KMT2D-Flag binding sites was performed using the ChIPpeakAnno package from the R software [49]. For statistical analysis of the overlap between KMT2D loci and $\mathrm{H} 3 \mathrm{~K} 4 \mathrm{me} 1$ or $\mathrm{H} 3 \mathrm{~K} 4 \mathrm{me} 1 / \mathrm{H} 3 \mathrm{~K} 27 \mathrm{ac}$ loci, 10,000 sets of equal numbers (1605) of loci with comparable widths across the genome were randomly generated and their overlapping with $\mathrm{H} 3 \mathrm{~K} 4 \mathrm{me} 1$ or $\mathrm{H} 3 \mathrm{~K} 4 \mathrm{me} 1 / \mathrm{H} 3 \mathrm{~K} 27 \mathrm{ac}$ loci 
was tested.

\section{MTT assays and colony formation assays}

For the MTT cell proliferation assay, cells were plated out in 96-well plates at a density of $1 \times 10^{4} /$ well in $200 \mu 1$ medium. $20 \mu 1$ MTT (Thiazolyl Blue Tetrazolium Bromide, $5 \mathrm{mg} / \mathrm{ml}$, Sigma-Aldrich, cat\# M5655) was added to each well and incubated for 3.5 hours. MTT solvent $(4 \mathrm{mM} \mathrm{HCl}, 0.1 \%$ Nondet P-40 (NP40) in isopropanol) was used to dissolve the pellets. Plates were read at $595 \mathrm{~nm}$. For D425MED, D283MED and HCT116 cell lines, the result from one representative experiment was shown. OD values from triplicate wells were presented as mean \pm sd. For DLD- 1 cell line, the result from three independent experiments was shown. P value was calculated by unpaired $t$ test. For the plate colony formation assay of HCT116 and DLD-1 cells, 500 cells in single cell suspension were plated out into each well of 6-well plate. Cells were allowed to grow for 12-14 days, then fixed with $1 \%$ formaldehyde and stained with $0.05 \%$ crystal violet solution, For medulloblastoma cells, a soft agar colony formation assay was performed. Briefly, $0.5 \%$ agar was used as the base agar and $1 \times 10^{3}$ cells in $0.25 \%$ top agar was plated in each well of a 6 -well plate. Colonies were counted after 14 days. For D425MED cell lines, the result from one representative experiment (triplicate wells) was shown. P value was calculated by unpaired $t$ test.

\section{Cell migration assays}

Transwell chamber assay was used to examine migration of the cells. 24-well plates with $6.5 \mathrm{~mm}$ inserts ( $8.0 \mu \mathrm{m}$ pore size) (Corning, cat\# 3422) were used. The inserts were pre-coated with $1 \%$ gelatin. $1 \times 10^{5}$ cells in serum-free medium were added to the upper chamber. The lower chamber was filled with complete medium $(10 \%$ FBS). After 16 hours of incubation, the medium in the top chamber was removed. Cells on the upper surface of the inserts were wiped off with swabs. Cells on the lower surface of the inserts were stained with $0.5 \%$ crystal violet.

\section{Tumorigenicity analysis in xenograft models}

All experiments were approved by the Animal Care Committee of the Duke University Medical Center. Facility-bred athymic BALB/c nu/nu nude male mice, 4-6 weeks of age, were maintained at the Cancer Center Isolation Facility (CCIF) of the Duke Cancer Institute. Cancer cell lines were grown to $60-80 \%$ confluence, harvested, washed with PBS, and injected subcutaneously $\left(1 \times 10^{7}\right.$ cells per mouse) into the right flanks. Tumors were measured for their widths and lengths using a micro-caliper. Tumor volumes were calculated (width ${ }^{2} \times$ length $/ 2$ ). Tumors were first measured at day 4 post-implantation, and twice per week afterward. Survival endpoint was defined as the day when the tumor volume reached at least $1000 \mathrm{~mm}^{3}$ and at least five times the volume of the initial measurement. A Kaplan-Meier survival curve was plotted using SPSS.

\section{ACKNOWLEDGEMENTS}

We would like to thank Zhenghe Wang for somatic knockin construct for generating somatic knockin cell lines, and Kai Ge for the gift of anti-KMT2D antibody. We thank Martin Roskoski for help with the xenograft experiments, and Lauren Albritton for editing the manuscript. This work was supported by a National Comprehensive Cancer Network Young Investigator Award (YH), an AACR-Aflac Career Development Award for Pediatric Cancer Research (YH), the Pediatric Brain Tumor Foundation and the Preston Robert Tisch Brain Tumor Center.

\section{REFERENCES}

1. Sjoblom T, Jones S, Wood LD, Parsons DW, Lin J, Barber TD, Mandelker D, Leary RJ, Ptak J, Silliman N, Szabo S, Buckhaults P, Farrell C, Meeh P, Markowitz SD, Willis J, et al. The consensus coding sequences of human breast and colorectal cancers. Science. 2006; 314(5797):268-274.

2. Dalgliesh GL, Furge K, Greenman C, Chen L, Bignell G, Butler A, Davies H, Edkins S, Hardy C, Latimer C, Teague J, Andrews J, Barthorpe S, Beare D, Buck G, Campbell PJ, et al. Systematic sequencing of renal carcinoma reveals inactivation of histone modifying genes. Nature. 2010; 463(7279):360-363.

3. Fujimoto A, Totoki Y, Abe T, Boroevich KA, Hosoda F, Nguyen HH, Aoki M, Hosono N, Kubo M, Miya F, Arai Y, Takahashi H, Shirakihara T, Nagasaki M, Shibuya T, Nakano K, et al. Whole-genome sequencing of liver cancers identifies etiological influences on mutation patterns and recurrent mutations in chromatin regulators. Nat Genet. 2012; 44(7):760-764.

4. Grasso CS, Wu YM, Robinson DR, Cao X, Dhanasekaran SM, Khan AP, Quist MJ, Jing X, Lonigro RJ, Brenner JC, Asangani IA, Ateeq B, Chun SY, Siddiqui J, Sam L, Anstett $\mathrm{M}$, et al. The mutational landscape of lethal castrationresistant prostate cancer. Nature. 2012; 487(7406):239-243.

5. Gui Y, Guo G, Huang Y, Hu X, Tang A, Gao S, Wu R, Chen C, Li X, Zhou L, He M, Li Z, Sun X, Jia W, Chen J, Yang S, et al. Frequent mutations of chromatin remodeling genes in transitional cell carcinoma of the bladder. Nat Genet. 2011; 43(9):875-878.

6. Hammerman PS, Hayes DN, Wilkerson MD, Schultz N, Bose R, Chu A, Collisson EA, Cope L, Creighton CJ, Getz G, Herman JG, Johnson BE, Kucherlapati R, Ladanyi M, Maher CA, Robertson G, et al. Comprehensive genomic 
characterization of squamous cell lung cancers. Nature. 2012; 489(7417):519-525.

7. Liu J, Lee W, Jiang Z, Chen Z, Jhunjhunwala S, Haverty PM, Gnad F, Guan Y, Gilbert H, Stinson J, Klijn C, Guillory J, Bhatt D, Vartanian S, Walter K, Chan J, et al. Genome and transcriptome sequencing of lung cancers reveal diverse mutational and splicing events. Genome Res. 2012; 22(12):2315-2327.

8. Morin RD, Mendez-Lago M, Mungall AJ, Goya R, Mungall KL, Corbett RD, Johnson NA, Severson TM, Chiu R, Field M, Jackman S, Krzywinski M, Scott DW, Trinh DL, Tamura-Wells J, Li S, et al. Frequent mutation of histonemodifying genes in non-Hodgkin lymphoma. Nature. 2011; 476(7360):298-303.

9. Pasqualucci L, Trifonov V, Fabbri G, Ma J, Rossi D, Chiarenza A, Wells VA, Grunn A, Messina M, Elliot O, Chan J, Bhagat G, Chadburn A, Gaidano G, Mullighan CG, Rabadan R, et al. Analysis of the coding genome of diffuse large B-cell lymphoma. Nat Genet. 2011; 43(9):830-837.

10. Watanabe Y, Castoro RJ, Kim HS, North B, Oikawa R, Hiraishi T, Ahmed SS, Chung W, Cho MY, Toyota M, Itoh F, Estecio MR, Shen L, Jelinek J and Issa JP. Frequent alteration of MLL3 frameshift mutations in microsatellite deficient colorectal cancer. PLoS One. 2011; 6(8):e23320.

11. Zang ZJ, Cutcutache I, Poon SL, Zhang SL, McPherson JR, Tao J, Rajasegaran V, Heng HL, Deng N, Gan A, Lim KH, Ong CK, Huang D, Chin SY, Tan IB, Ng CC, et al. Exome sequencing of gastric adenocarcinoma identifies recurrent somatic mutations in cell adhesion and chromatin remodeling genes. Nat Genet. 2012; 44(5):570-574.

12. van Haaften G, Dalgliesh GL, Davies H, Chen L, Bignell G, Greenman C, Edkins S, Hardy C, O’Meara S, Teague J, Butler A, Hinton J, Latimer C, Andrews J, Barthorpe S, Beare D, et al. Somatic mutations of the histone H3K27 demethylase gene UTX in human cancer. Nat Genet. 2009; 41(5):521-523.

13. Parsons DW, Li M, Zhang X, Jones S, Leary RJ, Lin JC, Boca SM, Carter H, Samayoa J, Bettegowda C, Gallia GL, Jallo GI, Binder ZA, Nikolsky Y, Hartigan J, Smith $\mathrm{DR}$, et al. The genetic landscape of the childhood cancer medulloblastoma. Science. 2011; 331(6016):435-439.

14. Pugh TJ, Weeraratne SD, Archer TC, Pomeranz Krummel DA, Auclair D, Bochicchio J, Carneiro MO, Carter SL, Cibulskis K, Erlich RL, Greulich H, Lawrence MS, Lennon NJ, McKenna A, Meldrim J, Ramos AH, et al. Medulloblastoma exome sequencing uncovers subtypespecific somatic mutations. Nature. 2012; 488(7409):106110.

15. Robinson G, Parker M, Kranenburg TA, Lu C, Chen X, Ding L, Phoenix TN, Hedlund E, Wei L, Zhu X, Chalhoub N, Baker SJ, Huether R, Kriwacki R, Curley $\mathrm{N}$, Thiruvenkatam $\mathrm{R}$, et al. Novel mutations target distinct subgroups of medulloblastoma. Nature. 2012; 488(7409):43-48.

16. Dubuc AM, Remke M, Korshunov A, Northcott PA, Zhan
SH, Mendez-Lago M, Kool M, Jones DT, Unterberger A, Morrissy AS, Shih D, Peacock J, Ramaswamy V, Rolider A, Wang X, Witt H, et al. Aberrant patterns of H3K4 and H3K27 histone lysine methylation occur across subgroups in medulloblastoma. Acta Neuropathol. 2013; 125(3):373384.

17. Jones DT, Jager N, Kool M, Zichner T, Hutter B, Sultan M, Cho YJ, Pugh TJ, Hovestadt V, Stutz AM, Rausch T, Warnatz HJ, Ryzhova M, Bender S, Sturm D, Pleier $\mathrm{S}$, et al. Dissecting the genomic complexity underlying medulloblastoma. Nature. 2012; 488(7409):100-105.

18. Grasso CS, Wu YM, Robinson DR, Cao X, Dhanasekaran SM, Khan AP, Quist MJ, Jing X, Lonigro RJ, Brenner JC, Asangani IA, Ateeq B, Chun SY, Siddiqui J, Sam L, Anstett $\mathrm{M}$, et al. The mutational landscape of lethal castrationresistant prostate cancer. Nature. 2012; 487(7406): 239-243

19. Liu P, Morrison C, Wang L, Xiong D, Vedell P, Cui P, Hua X, Ding F, Lu Y, James M, Ebben JD, Xu H, Adjei AA, Head K, Andrae JW, Tschannen MR, et al. Identification of somatic mutations in non-small cell lung carcinomas using whole-exome sequencing. Carcinogenesis. 2012; 33(7): 1270-1276.

20. Ng SB, Bigham AW, Buckingham KJ, Hannibal MC, McMillin MJ, Gildersleeve HI, Beck AE, Tabor HK, Cooper GM, Mefford HC, Lee C, Turner EH, Smith JD, Rieder MJ, Yoshiura K, Matsumoto N, et al. Exome sequencing identifies MLL2 mutations as a cause of Kabuki syndrome. Nat Genet. 2010; 42(9):790-793.

21. Zaidi S, Choi M, Wakimoto H, Ma L, Jiang J, Overton JD, Romano-Adesman A, Bjornson RD, Breitbart RE, Brown KK, Carriero NJ, Cheung YH, Deanfield J, DePalma S, Fakhro KA, Glessner J, et al. De novo mutations in histonemodifying genes in congenital heart disease. Nature. 2013; 498(7453):220-223.

22. Ruthenburg AJ, Allis CD and Wysocka J. Methylation of lysine 4 on histone $\mathrm{H} 3$ : intricacy of writing and reading a single epigenetic mark. Mol Cell. 2007; 25(1):15-30.

23. Muntean AG and Hess JL. The pathogenesis of mixedlineage leukemia. Annu Rev Pathol. 2012; 7:283-301.

24. Natarajan TG, Kallakury BV, Sheehan CE, Bartlett MB, Ganesan N, Preet A, Ross JS and Fitzgerald KT. Epigenetic regulator MLL2 shows altered expression in cancer cell lines and tumors from human breast and colon. Cancer Cell Int. 2010; 10:13.

25. Glaser S, Schaft J, Lubitz S, Vintersten K, van der Hoeven F, Tufteland KR, Aasland R, Anastassiadis K, Ang SL and Stewart AF. Multiple epigenetic maintenance factors implicated by the loss of M112 in mouse development. Development. 2006; 133(8):1423-1432.

26. Lubitz S, Glaser S, Schaft J, Stewart AF and Anastassiadis $\mathrm{K}$. Increased apoptosis and skewed differentiation in mouse embryonic stem cells lacking the histone methyltransferase M112. Mol Biol Cell. 2007; 18(6):2356-2366.

27. Andreu-Vieyra CV, Chen R, Agno JE, Glaser S, 
Anastassiadis K, Stewart AF and Matzuk MM. MLL2 is required in oocytes for bulk histone 3 lysine 4 trimethylation and transcriptional silencing. PLoS Biol. 2010; 8(8):e1000453.

28. Cho YW, Hong T, Hong S, Guo H, Yu H, Kim D, Guszczynski T, Dressler GR, Copeland TD, Kalkum M and Ge K. PTIP associates with MLL3- and MLL4-containing histone H3 lysine 4 methyltransferase complex. J Biol Chem. 2007; 282(28):20395-20406.

29. Issaeva I, Zonis Y, Rozovskaia T, Orlovsky K, Croce CM, Nakamura T, Mazo A, Eisenbach L and Canaani E. Knockdown of ALR (MLL2) reveals ALR target genes and leads to alterations in cell adhesion and growth. Mol Cell Biol. 2007; 27(5):1889-1903.

30. Goo YH, Sohn YC, Kim DH, Kim SW, Kang MJ, Jung DJ, Kwak E, Barlev NA, Berger SL, Chow VT, Roeder RG, Azorsa DO, Meltzer PS, Suh PG, Song EJ, Lee KJ, et al. Activating signal cointegrator 2 belongs to a novel steadystate complex that contains a subset of trithorax group proteins. Mol Cell Biol. 2003; 23(1):140-149.

31. Ansari KI, Hussain I, Shrestha B, Kasiri S and Mandal SS. HOXC6 Is transcriptionally regulated via coordination of MLL histone methylase and estrogen receptor in an estrogen environment. J Mol Biol. 2011; 411(2):334-349.

32. Lee J, Saha PK, Yang QH, Lee S, Park JY, Suh Y, Lee SK, Chan L, Roeder RG and Lee JW. Targeted inactivation of MLL3 histone H3-Lys-4 methyltransferase activity in the mouse reveals vital roles for MLL3 in adipogenesis. Proc Natl Acad Sci U S A. 2008; 105(49):19229-19234.

33. Cho YW, Hong S, Jin Q, Wang L, Lee JE, Gavrilova O and Ge K. Histone methylation regulator PTIP is required for PPARgamma and C/EBPalpha expression and adipogenesis. Cell Metab. 2009; 10(1):27-39.

34. Lee S, Kim DH, Goo YH, Lee YC, Lee SK and Lee JW. Crucial roles for interactions between MLL3/4 and INI1 in nuclear receptor transactivation. Mol Endocrinol. 2009; 23(5):610-619.

35. Guo C, Chang CC, Wortham M, Chen LH, Kernagis DN, Qin X, Cho YW, Chi JT, Grant GA, McLendon RE, Yan H, Ge K, Papadopoulos N, Bigner DD and He Y. Global identification of MLL2-targeted loci reveals MLL2's role in diverse signaling pathways. Proc Natl Acad Sci U S A. 2012; 109(43):17603-17608.

36. Lee J, Kim DH, Lee S, Yang QH, Lee DK, Lee SK, Roeder RG and Lee JW. A tumor suppressive coactivator complex of p53 containing ASC-2 and histone H3-lysine-4 methyltransferase MLL3 or its paralogue MLL4. Proc Natl Acad Sci U S A. 2009; 106(21):8513-8518.

37. Farioli-Vecchioli S, Cina I, Ceccarelli M, Micheli L, Leonardi L, Ciotti MT, De Bardi M, Di Rocco C, Pallini $\mathrm{R}$, Cavallaro $\mathrm{S}$ and Tirone F. Tis 21 knock-out enhances the frequency of medulloblastoma in Patched1 heterozygous mice by inhibiting the Cxcl3-dependent migration of cerebellar neurons. J Neurosci. 2012; 32(44):15547-15564.
38. Farioli-Vecchioli S, Micheli L, Leonardi L, Ceccarelli M, Cavallaro S and Tirone F. Medulloblastoma or not? Crucial role in tumorigenesis of the timing of migration of cerebellar granule precursor cells, regulated by Nos 2 and Tis21. Front Neurosci. 2012; 6:198.

39. Haag D, Zipper P, Westrich V, Karra D, Pfleger K, Toedt G, Blond F, Delhomme N, Hahn M, Reifenberger J, Reifenberger $G$ and Lichter P. Nos2 inactivation promotes the development of medulloblastoma in Ptch1(+/-) mice by deregulation of Gap43-dependent granule cell precursor migration. PLoS Genet. 2012; 8(3):e1002572.

40. Heintzman ND, Stuart RK, Hon G, Fu Y, Ching CW, Hawkins RD, Barrera LO, Van Calcar S, Qu C, Ching KA, Wang W, Weng Z, Green RD, Crawford GE and Ren B. Distinct and predictive chromatin signatures of transcriptional promoters and enhancers in the human genome. Nat Genet. 2007; 39(3):311-318.

41. Myers RM, Stamatoyannopoulos J, Snyder M, Dunham I, Hardison RC, Bernstein BE, Gingeras TR, Kent WJ, Birney E, Wold B and Crawford GE. A user's guide to the encyclopedia of DNA elements (ENCODE). PLoS Biol. 2011; 9(4):e1001046.

42. Hu D, Gao X, Morgan MA, Herz HM, Smith ER and Shilatifard A. The MLL3/MLL4 branch of the COMPASS family is a major $\mathrm{H} 3 \mathrm{~K} 4$ monomethylase at enhancers. Mol Cell Biol. 2013 Sep 30 (Epub ahead of print).

43. Bulger M and Groudine M. Functional and mechanistic diversity of distal transcription enhancers. Cell. 2011; 144(3):327-339.

44. Herz HM, Mohan M, Garruss AS, Liang K, Takahashi YH, Mickey K, Voets O, Verrijzer CP and Shilatifard A. Enhancer-associated H3K4 monomethylation by Trithoraxrelated, the Drosophila homolog of mammalian M113/M114. Genes Dev. 2012; 26(23):2604-2620.

45. Loven J, Hoke HA, Lin CY, Lau A, Orlando DA, Vakoc CR, Bradner JE, Lee TI and Young RA. Selective inhibition of tumor oncogenes by disruption of super-enhancers. Cell. 2013; 153(2):320-334.

46. Akhtar-Zaidi B, Cowper-Sal-lari R, Corradin O, Saiakhova A, Bartels CF, Balasubramanian D, Myeroff L, Lutterbaugh J, Jarrar A, Kalady MF, Willis J, Moore JH, Tesar PJ, Laframboise T, Markowitz S, Lupien M, et al. Epigenomic enhancer profiling defines a signature of colon cancer. Science. 2012; 336(6082):736-739.

47. Dawson MA and Kouzarides T. Cancer epigenetics: from mechanism to therapy. Cell. 2012; 150(1):12-27.

48. Zhang Y, Liu T, Meyer CA, Eeckhoute J, Johnson DS, Bernstein BE, Nusbaum C, Myers RM, Brown M, Li W and Liu XS. Model-based analysis of ChIP-Seq (MACS). Genome Biol. 2008; 9(9):R137.

49. Zhu LJ, Gazin C, Lawson ND, Pages H, Lin SM, Lapointe DS and Green MR. ChIPpeakAnno: a Bioconductor package to annotate ChIP-seq and ChIP-chip data. BMC bioinformatics. 2010; 11:237. 